\title{
Degradação de fachadas revestidas em argamassas nos edifícios de Brasília, Brasil
}

\author{
Degradation of rendered facades in the buildings of \\ Brasília, Brazil
}

\begin{abstract}
Elton Bauer
Jéssica Siqueira Souza

Larissa Mara Gonçalves Mota

\section{Resumo}

A

incidência de agentes de degradação sobre os edifícios é responsável pela origem de mecanismos de degradação que levam ao desenvolvimento de anomalias, as quais reduzem o desempenho dos sistemas do edifício. Nesse contexto, investigar a relação entre anomalias, agentes e mecanismos é fundamental para fornecer subsídios para estudos de vida útil e desenvolvimento de materiais e elementos mais duráveis. $\mathrm{O}$ objetivo deste estudo é investigar a gravidade e a extensão da degradação de fachadas revestidas em argamassa, identificando padrões que possam condicionar a degradação desse elemento. Essa abordagem se baseia na inspeção de edifícios em uso, e para isso se emprega o Método de Mensuração da Degradação. A metodologia é aplicada ao estudo de 90 amostras de fachada em edifícios de idade entre 20 e 60 anos localizadas localizados em Brasília, Brasil. As análises são baseadas em indicadores de degradação, quantificados a partir das variáveis investigadas, em específico a orientação solar e as zonas da fachada. Os resultados permitem a identificação de padrões típicos de degradação. A fissura é a anomalia que mais degrada as fachadas. Topo é a zona da fachada onde ocorre maior gravidade de degradação. Já a maior incidência de degradação ocorre na zona de paredes contínuas. Tem-se que as orientações norte e sul são as mais degradadas.
\end{abstract}

Palavras-chave: Degradação. Durabilidade. Anomalias. Fachadas. Argamassa.

${ }^{1}$ Elton Bauer ${ }^{1}$ Universidade de Brasília Brasília - DF - Brasil

${ }^{2}$ Jéssica Siqueira Souza 2Universidade de Brasília Brasília - DF - Brasil

${ }^{3}$ Larissa Mara Gonçalves Mota ${ }^{3}$ Universidade de Brasília Brasília - DF - Brasil

Recebido em 04/09/20

Aceito em 04/01/21

\section{Abstract}

The incidence of degradation agents on buildings engenders degradation mechanisms which lead to the development of anomalies that impair the performance of the building's systems. Hence, investigating the relationship between anomalies, agents and mechanisms is essential to provide valuable information for studies on service life and the development of more durable materials, components and elements. The aim of this study is to investigate the severity and extent of the degradation of rendered facades, identifying patterns that may affect their degradation. This study's approach is based on the inspection of buildings in use, using the Degradation Measurement Method. The method is applied to analyse 90 facade samples from buildings aged between 20 and 60 years, in the Brazilian capital, Brasilia. The analyses made were based on degradation indicators quantified from the investigated variables, especially solar orientation, and the facade zones of the samples. The results led to the identification of typical degradation patterns. Cracking is the anomaly that most degrades facades. The top area is the facade zone where the most severe degradation occurs. The highest incidence of degradation occurs in the continuous walls. The most degraded facades are the north and south facing ones.

Keywords: Dagradation. Durability. Anomalies. Rendered facades. Mortar.

BAUER, E.; SOUZA, J. S.; MOTA, L. M. G. Degradação de fachadas revestidas em argamassas nos edifícios de Brasília, 23 Brasil. Ambiente Construído, Porto Alegre, v. 21, n. 4, p. 23-43, out./dez. 2021. ISSN 1678-8621 Associação Nacional de Tecnologia do Ambiente Construído. http: //dx.doi.org/10.1590/s1678-86212021000400557 


\section{Introdução}

O edifício e seus elementos são submetidos a um grande conjunto de ações e agentes ao longo da vida. Essas ações sobre o edifício se correlacionam principalmente às funções para as quais ele foi projetado e construído, e também a como se comporta ante esse conjunto complexo de agentes e condicionantes de seu desempenho (FLORES-COLEN, 2009; GASPAR; BRITO, 2008). Nesse contexto, as ações de degradação têm grande importância, uma vez que atuam sobre a possível diminuição do desempenho ao longo do tempo, delimitando, assim, a vida útil do edifício ou de seus elementos (ABNT, 2013; BRITISH..., 2012). A degradação é entendida como um processo em que agentes causam a deterioração de uma ou de várias propriedades dos elementos do edifício, sendo sua ação geralmente evolutiva em relação ao tempo (BRITISH..., 2010; INTERNATIONAL..., 2004).

As falhas que ocorrem nos edifícios geralmente são analisadas em relação às prováveis causas, bem como quanto à evolução da degradação ao longo do tempo (GASPAR; BRITO, 2008; SANTOS, 2018; PEREIRA et al., 2020). Elas se caracterizam por ocorrer em situações em que o desempenho esperado não é mais alcançado pelo elemento ou sistema do edifício.

A terminologia para falhas é ampla, e são correntes termos patologia, defeito, manifestação patológica, anomalia, entre outros (INTERNATIONAL..., 2013; BRITISH..., 2010). Neste estudo é empregado o termo "anomalia" para caracterizar as falhas ou defeitos, uma vez que sua presença causa uma perturbação anômala ao desempenho (diminuição da vida útil, fim da funcionalidade).

As definições de projeto e construção envolvendo nível de desempenho estabelecido, grau de proteção aos agentes de degradação bem como também a qualidade dos processos e materiais, influem diretamente no envelhecimento natural e no desgaste pelo uso, como enfatiza Cóias (2009). O processo de degradação evolui ao longo do tempo, e quando se alcança a vida útil o desempenho cai abaixo de seu limite mínimo (SOUZA et al., 2020).

Para se alcançar a vida útil estabelecida, várias ações devem ser associadas a processos de manutenção e devem ser inseridas em programas de gestão da manutenção, como sugerem Flores-Colen, Brito e Freitas (2008) e Madureira et al. (2017). Falhas de construção, anomalias precoces ou não esperadas (acidentes, ações não previstas) não são decorrentes da degradação. Nesses casos, o restabelecimento do desempenho se associa à manutenção corretiva, em um processo de reparação.

A correção das anomalias se caracteriza pelo retorno às condições aceitáveis de desempenho pela reconstrução, substituição ou reabilitação dos elementos ou área degradada (BRITISH..., 2010). Ao longo da vida útil do elemento ou do sistema, ocorre também a questão da obsolescência (técnica, funcional, estética), quando as intervenções decorrem de novas exigências, novos equipamentos ou mudança de uso do edifício. Como a vida útil dos edifícios perdura várias décadas, é relativamente frequente que a obsolescência delimite a vida útil de vários sistemas e elementos (BRITISH..., 2011; INTERNATIONAL..., 2013).

As fachadas têm papel fundamental no desempenho e durabilidade do edifício, uma vez que fazem parte do envelope exterior e são submetidas constantemente a ações intensas do clima (SILVA et al., 2013; BAUER et al., 2020). Têm como função proteger ou amenizar essas ações para os ambientes internos do edifício. Esse sistema é constantemente exposto a ação de agentes climáticos de degradação, em que a radiação solar, a temperatura, a chuva dirigida e o vento podem ser considerados como os principais responsáveis pela degradação (INTERNATIONAL..., 2004; SOUZA, 2019).

A degradação de fachadas, por sua vez, é decorrente de múltiplos fatores, que atuam de forma simultânea e sinérgica, influenciando nos mecanismos de degradação (SILVESTRE; BRITO, 2009; DIAS et al., 2014; BAUER; CASTRO; SILVA, 2015). Esses mecanismos são processos que causam alterações, ao longo do tempo, na composição ou microestrutura do elemento ou material, gerando as anomalias (BRITISH..., 2010). Os agentes de degradação influem diretamente nos mecanismos e são classificados em mecânicos, eletromagnéticos, térmicos, químicos e biológicos (AMERICAN..., 1996). A ação dos agentes e mecanismos depende diretamente das características do projeto e da construção, onde a especificação de materiais e sistemas deve ser adequadamente definida para se alcançar o desempenho e vida útil especificados (ADDESSI et al., 2020).

As alvenarias e fachadas possuem seus mecanismos e agentes de degradação particularizados a seu comportamento. Para as alvenarias, os agentes estruturais são as sobrecargas, assentamentos de fundação e deformações impostas pela estrutura. Esses geram fissuras, deformações permanentes, esmagamentos e colapso dos componentes dos revestimentos, argamassas e tijolos (CÓIAS, 2009). Os agentes físicos são oriundos de ações térmicas, que causam deformações excessivas e fissuras nas alvenarias. Também ocorre 
cristalização de sais, erosão e abrasão, que causam escamação, desagregação e pulverulência. Para os agentes químicos se destaca a ação de agentes agressivos, como sulfatos, sais e ácidos, que causam incrustações, manchamento, escorrimentos, desagregação e fragmentação da alvenaria. Os agentes biológicos, basicamente, atuam pela formação de micro-organismos, como os fungos emboloradores (SANTOS, 2019). Estes causam manchas, descolorações e descascamentos na superfície das fachadas. Para agentes e mecanismos associados ao uso se mencionam ações específicas de abrasão e desgaste, principalmente em ambientes de grande tráfego de pessoas, com casos de pulverulência e fissuração das argamassas de revestimento.

A evolução da degradação ao longo do tempo, e pela ação contínua dos agentes de degradação, é acompanhada por alterações dos mecanismos iniciais causadores das anomalias (SÁ et al., 2015). A Figura 1 ilustra um exemplo dessa alteração.

Em idades jovens a fissura se apresenta de uma forma pouco crítica, prejudicando em essência aspectos estéticos (Figura 1a). Com o passar do tempo, em função da ação contínua dos agentes de degradação climáticos, a fissuração se amplia em gravidade, já com maior área de ocorrência (Figura 1b). Evoluindo o processo, a fissuração se incrementa e facilita o surgimento de outras anomalias, como descolamento, pulverulência e eflorescência (Figura 1c). Observa-se, portanto, que os mecanismos se modificam e contribuem sinergicamente para o aumento da gravidade e extensão das anomalias. Assim, é necessário o estudo das anomalias sob a ótica da propagação da degradação para poder quantificar a vida útil das fachadas.

\section{Mecanismos e agentes de degradação}

As anomalias de fachada decorrem da ação dos agentes de degradação, os quais, por mecanismos específicos, levam à degradação ou queda de desempenho. Os mecanismos são vinculados às definições do projeto e construção (materiais, cura, espessuras, prazos, entre outros), podendo estar associados a condições agravantes ou atenuantes (CAVALAGLI et al., 2019). Uma situação agravante pode ser exemplificada pela existência de fissuras, que incrementam a ação da chuva dirigida em uma fachada (RAMIREZ et al., 2019). Outra situação, agora atenuante, pode ser exemplificada pela condição abrigada em relação à radiação solar, o que leva à menor ocorrência de deformações de natureza térmica, e possível menor fissuração da argamassa.

Um padrão universal para as anomalias de fachada não pode ser definido. Variações de clima e, consequentemente, dos agentes de degradação climáticos, diferenças nas técnicas de projeto e construção, diferenças nos códigos de construção levam obviamente a resultados distintos e específicos. Assim, as respostas que se obtêm nos mapeamentos, inspeções e investigações de anomalias devem ser estudadas no contexto em que se inserem (SÁ et al., 2015; MADUREIRA et al., 2017). Diferenças entre países ou regiões levam sempre a resultados específicos. Por sua vez, o que se pode generalizar são os mecanismos que dependem essencialmente da natureza e intensidade dos agentes, e, ainda, das características e propriedades dos elementos e dos materiais.

\section{Figura 1 - Exemplo das etapas evolutivas da degradação por fissuração}

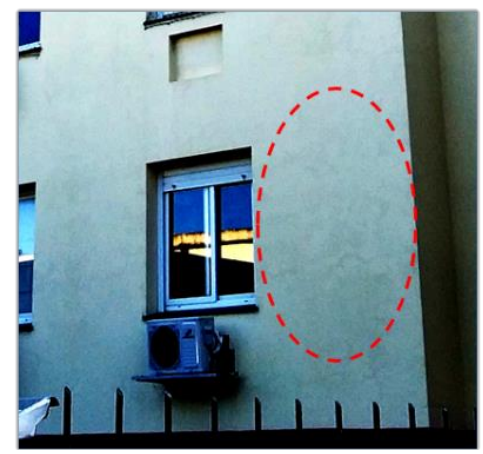

(a) Sintomas iniciais

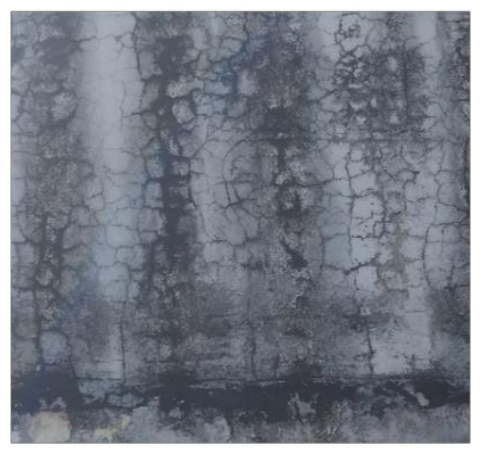

(b) Propagação da fissuração

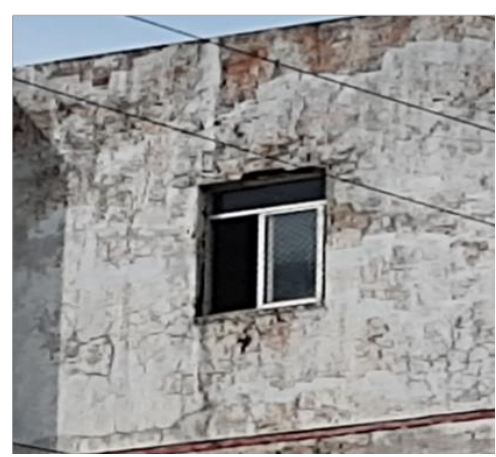

(c) Degradação generalizada 
As anomalias de fachada são associadas à degradação pelos agentes de degradação, principalmente os climáticos, em mecanismos específicos. Os agentes geralmente possuem ação sinérgica, o que permite combinações de como eles podem atuar na degradação (SÁ et al., 2015; PEREIRA et al., 2020). O Quadro 1 apresenta os principais mecanismos, agentes principais e coadjuvantes no desenvolvimento das anomalias e em sua propagação.

Para o caso dos descolamentos se identificam no Quadro 1 como mecanismos a deformação da base, a cristalização de sais e a retração das argamassas. Deve ser mencionado que essa anomalia é muito suscetível a erros construtivos e de projeto (falhas de aderência, espessura excessiva, entre outros), os quais não são oriundos da degradação. Os principais agentes são esforços de diversas naturezas (mecânicos e térmicos), e pode haver associação também com chuva dirigida, temperaturas e incidência de ventos. Para a propagação da degradação por descolamento, as deformações da base, os ciclos de umidificação e secagem e as incidências de temperatura elevadas incrementam a extensão e gravidade das anomalias (PEREIRA; DE BRITO; SILVESTRE, 2018; RAMIREZ et al., 2019).

Para as fissuras se observa também influência da base (alvenaria), principalmente por concentração de esforços e deformações diferenciais entre camadas e em relação à base. A cristalização de sais da alvenaria é também um mecanismo com origem na base. Na fissuração os agentes são variados, desde os associados aos esforços da base até os ligados à retração e à cristalização de sais (secagem). Os efeitos cíclicos de molhagem e secagem, bem como de esforços e deformações incrementam a propagação da degradação (FLORES-COLEN et al., 2016).

A pulverulência está muito ligada às características das argamassas, particularmente sua formulação e porosidade. Sob efeito da água, esforços internos de expansão causam a desagregação com manifestação na superfície (PEREIRA; DE BRITO; SILVESTRE, 2018). Chuva dirigida e umidade ascensional podem se associar aos agentes, bem como a cristalização de sais e a formação de micro-organismos.

Para a eflorescência se observa o depósito superficial de sais, oriundos basicamente da alvenaria, argamassa ou do meio externo. Sais, água e secagem são os principais agentes, sendo também influenciados pela radiação solar, chuva dirigida e umidade ascensional (PEREIRA; DE BRITO; SILVESTRE, 2018). Na propagação ciclos de umidificação e secagem incrementam a degradação (FLORES-COLEN et al., 2016).

Os principais mecanismos do desenvolvimento de manchas mostrados no Quadro 1, molhagem, microorganismos e acúmulo de sujeiras, são intrinsicamente associados à umidade, particularmente a incidência de chuva dirigida, o molhamento das superfícies e o escorrimento da água. Efeitos de secagem são coadjuvantes aos processos. Para os micro-organismos (fungos emboloradores) associa-se também o pH da superfície, a umidade relativa e a luminosidade (SANTOS, 2019). Na propagação da degradação por manchas há os ciclos de molhagem e secagem, a presença de poluentes atmosféricos e o incremento do crescimento de micro-organismos.

As anomalias de pintura (descolamento, fissura e bolha) ocorrem por mecanismos específicos. O descolamento e a fissura dependem diretamente da degradação da película, onde o enrijecimento é um fator de importância. Radiação solar, ingresso de água (chuva dirigida) e cristalização de sais agem na degradação e permitem a evolução dos mecanismos (PEREIRA; DE BRITO; SILVESTRE, 2018). Nas bolhas, basicamente a umidade no substrato e a contaminação por sais são incrementadas em ciclos de umidificação e secagem nas fachadas.

\section{Anomalias: gravidade e importância}

A definição de parâmetros e índices de gravidade entre as anomalias é muito importante, principalmente quando se busca desenvolver e aplicar modelos de degradação. Identificar qual situação é a mais grave sempre é o foco de qualquer investigação. Além disso, obter índices quantitativos da gravidade entre as anomalias permite desenvolver todo um conjunto de análises, quer sob o enfoque da degradação geral da fachada (localização, orientação solar), quer sob o da degradação localizada (zonas de fachada). 
Quadro 1 - Mecanismos, agentes de degradação e propagação das anomalias de fachadas em argamassas

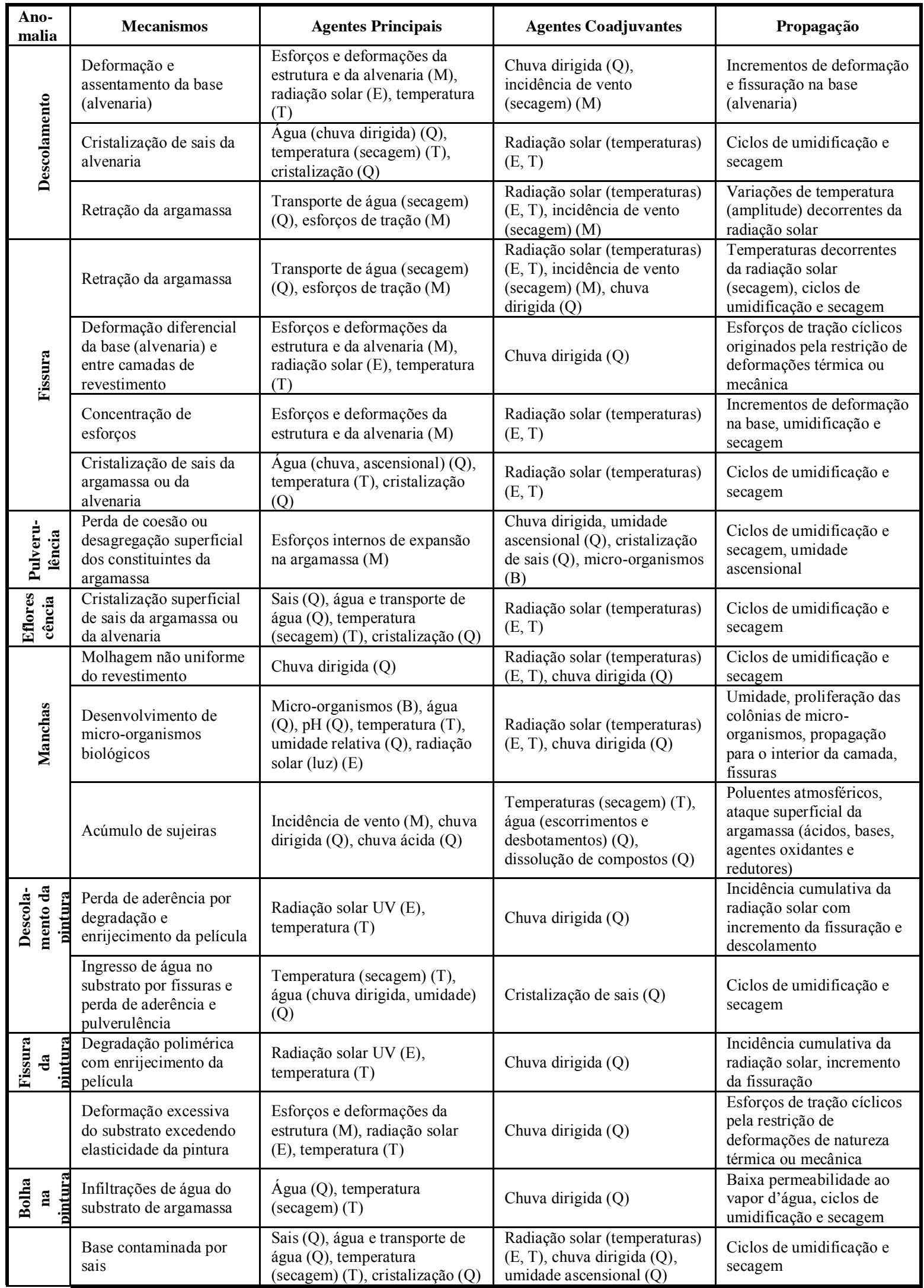

Nota: agentes: mecânicos $(M)$, eletromagnéticos $(E)$, térmicos $(T)$, químicos $(Q)$, biológicos $(B)(B R I T I S H \ldots, 2011)$. 
Uma metodologia bastante empregada para ponderar e classificar as anomalias, proposta por Gaspar e Brito (2008, 2010), define a importância em relação ao custo de reparação que a anomalia demanda. Essa análise é fortemente justificada para a classificação de importância, mas esbarra nas diferenças econômicas e de tecnologias entre países e regiões. O que é significativo para os custos em um país pode ser diferente para outro. De modo a oferecer uma alternativa, Santos (2018) e Bauer et al. (2020) propõem um índice de importância relativa $\left(I_{R}\right)$ entre as anomalias empregando critérios de análise de causas das anomalias e análise de sua influência no desempenho. Desse estudo, o índice de importância relativa $\left(\mathrm{I}_{\mathrm{R}}\right)$ correlaciona quantitativamente as anomalias em relação à anomalia mais grave (fissura), a qual tem valor de $I_{R}$ igual a 1,00. A Tabela 1 apresenta os valores obtidos de $I_{R}$.

A fissuração é a anomalia de maior valor de $I_{R}$, seguida do descolamento e da pulverulência (Tabela 1). As anomalias menos relevantes são as fissuras de pintura e bolhas. Nessa questão é importante salientar que os índices obtidos não advêm de levantamentos e mapeamentos de campo, e sim de uma análise de causa e efeito com o emprego de matrizes de correlação. Essa quantificação é importante no desenvolvimento de modelos de degradação e permite um conjunto de análises, como a definição das condições de maior vulnerabilidade à degradação. Em relação à vida útil, a ocorrência das anomalias, suas causas e mecanismos têm grande importância, pois delimitam o tempo no qual o desempenho da fachada é aceitável. Sempre que se fala em vida útil e durabilidade, é necessário explicitar os agentes de degradação, uma vez que definem as condições de exposição a que o elemento é submetido. Assim, diferenças entre climas, localização, macro, meso e microclima se tornam de grande importância. As anomalias decorrentes são função direta desse conjunto de variáveis. Uma forma consagrada e largamente empregada para estudo da vida útil é o Método Fatorial (BRITISH..., 2012; INTERNATIONAL..., 2004; SOUZA, 2019), o qual se baseia na determinação da vida útil estimada a partir da vida útil de referência multiplicada por uma série de fatores adaptados a condições específicas de cada caso. Basicamente se pondera sobre condicionantes com efeito positivo e negativo na vida útil do elemento ou sistema. A Equação 1 descreve o modelo.

$\mathrm{VUE}=$ VUR.A.B.C.D.E.F.G

Eq. 1

Onde:

VUR é a vida útil de referência;

VUE é a vida útil estimada; e

A, B, C, D, E, F E G são os fatores de influência:

- A - qualidade de materiais;

- B - nível de projeto;

- C - nível de execução;

- D - condições internas;

- E-condições externas;

- F - ações de uso; e

- $\mathrm{G}$ - manutenção.

Tabela 1 - Índice de importância relativa $\left(I_{R}\right)$ das anomalias de fachada em argamassa

\begin{tabular}{c|c|c|c|c|c|c|c}
\hline \multicolumn{5}{c|}{ Argamassa } & \multicolumn{3}{c}{ Pintura } \\
\hline $\begin{array}{c}\text { Descola- } \\
\text { mento }\end{array}$ & Fissura & $\begin{array}{c}\text { Pulveru- } \\
\text { lência }\end{array}$ & $\begin{array}{c}\text { Eflores- } \\
\text { cência }\end{array}$ & Mancha & $\begin{array}{c}\text { Descola- } \\
\text { mento }\end{array}$ & Fissura & Bolha \\
\hline 0,85 & 1,00 & 0,44 & 0,29 & 0,24 & 0,19 & 0,07 & 0,08 \\
\hline
\end{tabular}


A vida útil de referência consiste na estimativa de vida do elemento em condições padrão de uso (BRITISH..., 2012). Essas condições se modificam para aplicações particulares, que são influenciadas pelos fatores. Se esses fatores afetam a vida útil (positiva ou negativamente), é evidente que também afetam as anomalias. Embora se conheça a influência do conjunto das variáveis intervenientes, muitas delas são difíceis de mensurar ou, ainda, não estão disponíveis. Mesmo que se saiba, por exemplo, que a manutenção é determinante na vida útil do elemento, na maioria das vezes há situações em que não há registro dela. Assim, a investigação passa a atuar com as variáveis de que se tem domínio e sobre as quais se investigam os comportamentos e evoluções, e não com variáveis não disponíveis. Souza et al. (2018) apresentam estudo da vida útil de fachadas pelo método fatorial (Equação 1) utilizando somente os fatores A, B e E. Portanto, importa avaliar quanto da degradação é explicada pelos fatores e condicionantes disponíveis para a análise.

O estudo comportamental das variáveis - e a observância das anomalias e degradação em edifícios similares - permite efetuar comparações e associações que são usadas em modelos de previsão de vida útil. A avaliação da vida útil por meio da inspeção de edifícios tem a vantagem de dar correlação direta entre o estado dos elementos e sistemas, o meio ambiente (exposição) e o uso do edifício (BRITISH... 2012). Dessa forma, um banco de dados com informações quantificadas de anomalias e da extensão da degradação dilui a complexidade em controlar, monitorar e medir todos os agentes atuantes, pois permite verificar uma ação da combinação dos agentes de degradação de forma conjunta. A resposta da evolução dessas anomalias e da degradação existente é o resultado da ação localizada de todos os fatores (Equação 1).

A investigação de campo, com a inspeção dos edifícios, a quantificação e o mapeamento das anomalias, permite detectar padrões e tendências que auxiliam no entendimento da degradação. O presente estudo tem como foco a avaliação da degradação tendo por base levantamentos e inspeções de edifícios em uso e submetidos às condições climáticas da região de Brasília, Brasil. O enfoque aborda edifícios com idades entre 20 e 60 anos, em que se busca quantificar a degradação para cada caso e associá-la à orientação solar de cada fachada. Outra análise feita é a quantificação da gravidade e da incidência de ocorrência das anomalias nas diferentes zonas da fachada. Nessa análise, o intuito é identificar as condições mais críticas em relação ao desenvolvimento de cada anomalia e quais comportamentos podem ser associados à degradação das fachadas.

\section{Métodos}

Uma das grandes preocupações quanto à investigação de campo diz respeito à homogeneidade da amostra a investigar, de modo que não sejam inseridas outras variáveis sobre as quais não se tem controle. A amostra de estudo constitui-se de edifícios situados em Brasília, Brasil, em que características importantes no conjunto arquitetônico e urbanístico são tombadas pela Unesco. Disso decorre que os edifícios seguem um padrão arquitetônico e que também há padronização da tecnologia construtiva. Assim, é factível comparar edifícios de idades diferenciadas, uma vez que existe uma padronização construtiva relevante.

Outro aspecto relacionado à homogeneidade da amostra diz respeito a características de clima. De acordo com a classificação de Köppen, o clima de Brasília é caracterizado como Tropical de Altitude (BAUER et al., 2020; MACIEL, 2002), onde são identificados dois períodos distintos: chuvoso e seco. Segundo o zoneamento bioclimático do território brasileiro proposto pela NBR 15220-3 (ABNT, 2005), que agrupa climas semelhantes, Brasília se localiza na Zona 4, que abrange 2\% do território nacional. É típica nesse caso uma condição relativamente árida com grandes variações de temperatura entre o dia e a noite. A amplitude térmica é maior no dia do que durante o ano. Ao se observarem os valores mensais da radiação e da chuva dirigida, a Figura 2 identifica nitidamente o período seco (maio a setembro) e o período chuvoso (outubro a abril).

A Figura 2 apresenta os dados característicos para um edifício de Brasília, obtidos a partir de uma simulação higrotérmica, com o emprego de um arquivo climático anual TMY da base EPW/ANTAC (RORIZ, 2012). Ao se efetuar a simulação higrotérmica, empregando o WUFI ${ }^{\circledR}$ Pro 5.3, se obtêm dados horários que são compilados em dados mensais médios para radiação total, e dados mensais acumulados para chuva dirigida. Para cada orientação da fachada é efetuada uma simulação pelo período de um ano. 
Figura 2 - (a) Radiação solar total média mensal e (b) chuva dirigida acumulada mensal observadas ao longo do ano (dados obtidos por simulação higrotérmica a partir de um TMY empregando o WUFI ${ }^{\circledR}$ Pro 5.3 para Brasília)

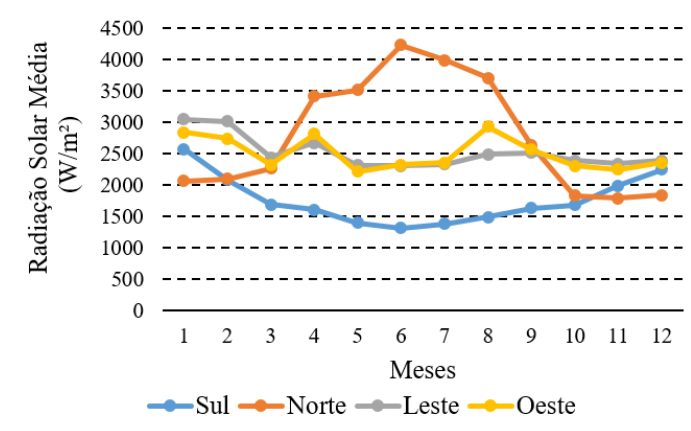

(a)

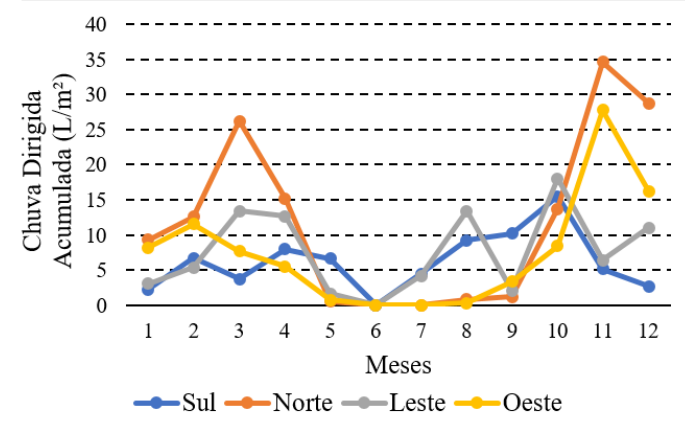

(b)

A fachada norte $(\mathrm{N})$ recebe alta incidência de radiação solar, principalmente no período de março a setembro. As fachadas leste $(\mathrm{L})$ e oeste $(\mathrm{O})$ recebem radiação solar em taxas similares durante todo o ano, com pouca variação entre o período seco e o chuvoso. A fachada sul (S) é a que recebe menos radiação ao longo do ano, principalmente pela não incidência solar entre os meses de março e setembro. A radiação solar, além de ser um agente de degradação, é responsável em grande parte pelas temperaturas observadas ao longo do dia na fachada. Conforme observado no Quadro 1, esforços e deformações, efeitos de secagem são atribuídos à ciclagem térmica, em muito decorrente dos efeitos da radiação incidente nas fachadas.

$\mathrm{O}$ comportamento da chuva dirigida é diferenciado ao longo do ano. Em termos anuais, as fachadas $\mathrm{N}$ e $\mathrm{O}$ são as que apresentam maior valor de chuva dirigida. Isso é muito evidente no período chuvoso, comportamento que pode ser explicado pela direção de ventos predominante durante as chuvas. Já no período seco as chuvas são dominantes nas orientações S e L. A incidência de chuva e a secagem se apresentam em quase todos os mecanismos das anomalias (Quadro 1), se não como ação principal, como ação coadjuvante. Na propagação, os ciclos de umidificação e secagem são importantes e incrementam fortemente a degradação.

\section{Banco de dados}

O objetivo do levantamento de campo é a investigação da degradação e das anomalias presentes nas fachadas. Dessa forma se busca identificar a influência da orientação solar e das respectivas zonas da fachada na degradação. Também se investiga qual é o comportamento da degradação para as diferentes anomalias. O conjunto de edifícios investigados é uma amostra uniforme com idades entre 20 e 60 anos, sendo as fachadas constituídas por alvenarias revestidas com argamassa e pintura. Cada fachada do edifício é decomposta em amostras (Figura 3a), e cada amostra é quantificada de forma individualizada. Neste estudo são estudadas 90 amostras, que compõem o banco de dados.

Cada amostra da fachada, como a amostra A1 da Figura 3a, é configurada segundo alguns critérios básicos. A área da amostra deverá estar entre $50 \mathrm{~m}$ e $300 \mathrm{~m}$, em um mesmo plano. Mudanças de plano, ou de orientação, já constituem outra amostra. Uma amostra não pode estar posicionada em dois ou mais elementos de arquitetura (fachada, empena, caixa de escadaria, torre). Obrigatoriamente, a amostra deverá estar em um mesmo elemento de arquitetura, como apontam Piazzarollo (2019) e Santos (2018).

A investigação e a quantificação da degradação das amostras em estudo são baseadas no Método de Mensuração da Degradação (MMD) (BAUER; SOUZA; PIAZAROLLO, 2020). As amostras em estudo são digitalizadas em imagem de alta resolução, sendo então ortogonalizadas de modo a definir uma escala para quantificação das áreas de anomalias, bem como da área das zonas de fachada e da área da amostra. As anomalias observadas são delimitadas, e em casos mais complexos se faz uma inspeção termográfica quantitativa para identificar, medir e definir o grau de dano para cada caso. 
Figura 3 - (a) Subdivisão da fachada em amostras individuais (A1, A2, A3); e (b) sobreposição de malha para quantificação das áreas degradadas

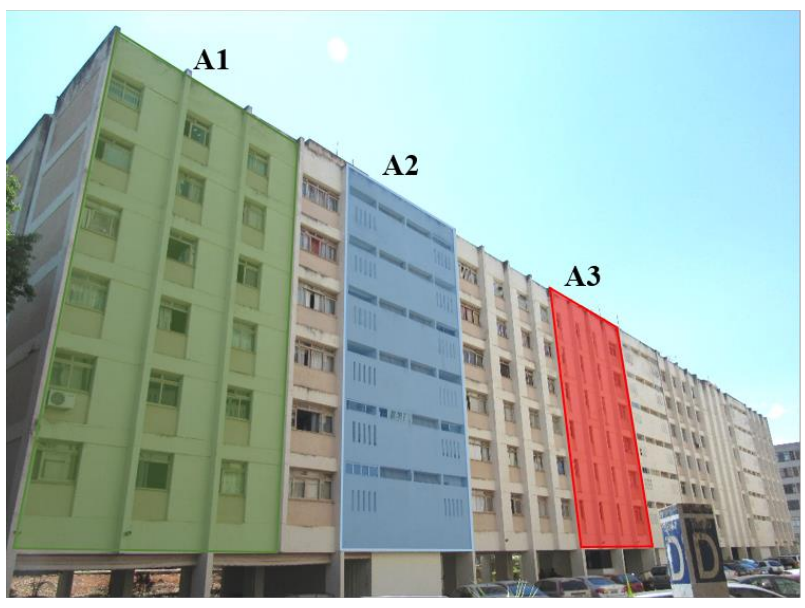

(a)

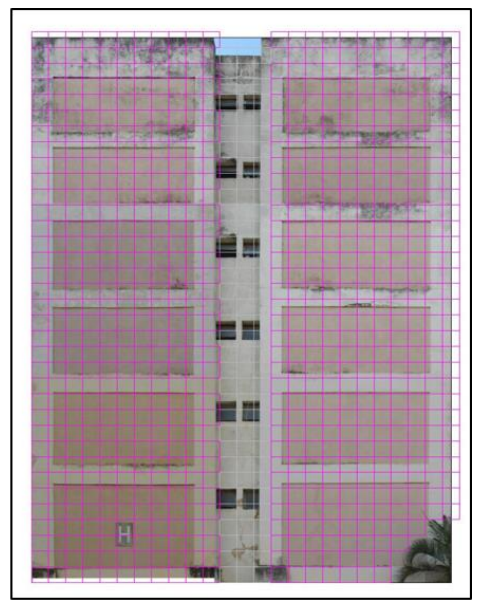

(b)

A quantificação da degradação pela mensuração da área degradada se faz com a sobreposição de uma malha com unidades nas dimensões de 0,50x0,50 m ao mapeamento da amostra, em escala. Após a sobreposição da malha, são definidos os andares e as zonas constituintes da fachada e são quantificados os detalhamentos da amostra. São quantificadas as unidades de malha que apresentam degradação. A Figura $3 b$ mostra a sobreposição da malha na amostra de fachada.

As anomalias investigadas são as mais relevantes para o sistema de revestimento em argamassas, já observadas em investigações anteriores (SANTOS et al., 2018; BAUER et al., 2020). O Quadro 2 apresenta a identificação das anomalias. Os principais mecanismos e agentes de degradação foram apresentados anteriormente, no Quardro 1.

O detalhamento da distribuição das anomalias nas amostras de fachada também é diferenciado em relação às zonas nas quais elas ocorrem. Para isso, a amostra é subdividida em cinco zonas, paredes contínuas (PC), aberturas (AB), cantos e extremidades (CE), transição entre pavimentos (TP) e topo (TO), conforme ilustra a Figura 4. A Tabela 2 define as características das zonas das amostras de fachada e apresenta o percentual médio observado para cada zona em relação ao total de amostras do banco de dados. Observa-se que PC apresenta maior percentual de área seguido de AB. A zona com menor ocorrência de área é TO.

A definição da orientação cardeal de cada amostra, no contexto das fachadas e do edifício, segue as definições já aplicadas em investigações anteriores (GARRIDO; PAULO; BRANCO, 2012; SILVA, 2014; SOUZA, 2016; SANTOS, 2018). São definidas as quatro orientações conforme os seguintes critérios do Quadro 3.

\section{Indicadores de degradação}

A degradação pode ser quantificada de várias formas, e para isso alguns indicadores podem auxiliar no entendimento da gravidade e da incidência de ocorrência das anomalias.

O Fator de Danos (FD) é um indicador geral de degradação e está associado à relação entre área degradada e área da amostra. Esse indicador é mais empregado para quantificar a incidência de ocorrência (frequência) das anomalias e da degradação. A quantificação das áreas degradadas geralmente é feita por anomalias, conforme coloca a Equação 2 .

$F D=\frac{\sum A_{z}}{A}=\frac{A_{D e . A}+A_{F i . A}+A_{P u . A}+A_{E f . A}+A_{M a . A}+A_{P i . A}}{A}$

Onde:

FD é o Fator de Danos;

$\mathrm{A}_{\mathrm{z}}$ é a área degradada por determinada anomalia em metros quadrados (De.A, Fi.A, Pu.A, Ef.A, Ma.A e Pi.A); e 
A é a área total da amostra (m ). Quando calculado para cada zona da fachada em específico, é denominado por Fator de Danos da Zona (Equação 4).

O FD pode também ser dividido e calculado para cada anomalia, sendo então denominado Fator de Danos da Anomalia, conforme a Equação 3.

$F D_{\text {anom }}=\frac{A_{\text {Danom }}}{A}$

Onde:

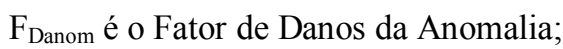

$\mathrm{A}_{\text {Danom }}$ é a área degradada por determinada anomalia $\left(\mathrm{m}^{2}\right)$; e

A é a área total da amostra (m).

A soma dos $\mathrm{FD}_{\text {anom }}$ corresponde ao FD (Equação 2).

Quadro 2 - Classificação e denominação das patologias

\begin{tabular}{|c|l|c|}
\hline Camada & \multicolumn{1}{|c|}{ Anomalia } & Denominação \\
\hline \multirow{4}{*}{ Argamassa } & Descolamento & De.A \\
\cline { 2 - 3 } & Fissura & Fi.A \\
\cline { 2 - 3 } & Pulverulência & Pu.A \\
\cline { 2 - 3 } & Eflorescência & Ef.A \\
\cline { 2 - 3 } & Manchas & Ma.A \\
\hline Pintura & Falha de pintura & Pi.A \\
\hline
\end{tabular}

Figura 4 - Definição das zonas das fachadas

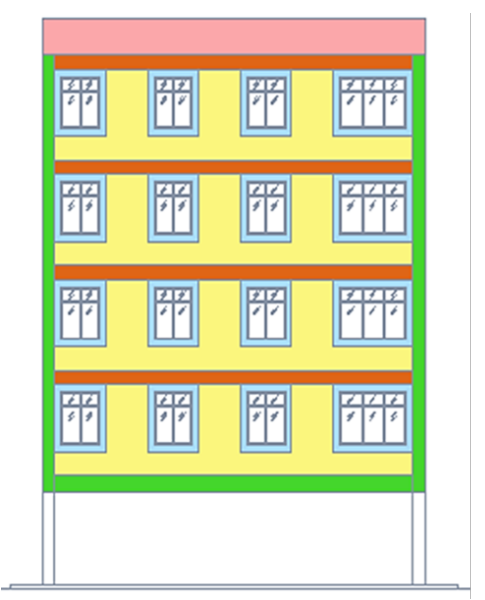

Aberturas (AB)

Cantos e Extremidades (CE)

Transição de Pavimentos (TP)

Topo (TO)

Paredes Contínuas (PC)

Tabela 2 - Definição das zonas das fachadas

\begin{tabular}{l|l|c}
\hline \multicolumn{1}{c|}{ Zona } & \multicolumn{1}{c}{ Descrição } & Percentual na amostra \\
\hline $\mathrm{PC}-$ Paredes contínuas & Áreas contínuas (alvenaria e painéis) & $37 \%$ \\
\hline $\mathrm{AB}-$ Aberturas & Áreas em torno de aberturas (portas e janelas) & $28 \%$ \\
\hline $\mathrm{CE}-$ Cantos e extremidades & $\begin{array}{l}\text { Áreas de contorno do plano de fachada, } \\
\text { extremidades e descontiuidades }\end{array}$ & $12 \%$ \\
\hline $\mathrm{TP}-$ Transição de pavimentos & Áreas esntre os pavimentos & $13 \%$ \\
\hline $\mathrm{TO}-$ Topo & Área superior no topo da fachada & $10 \%$ \\
\hline
\end{tabular}

Quadro 3 - Faixas de azimute para cada orientação

\begin{tabular}{|l|l|}
\hline \multicolumn{1}{|c|}{ Orientação } & \multicolumn{1}{c|}{ Azimute } \\
\hline Norte $-\mathrm{N}$ & $315^{\circ}$ a $44^{\circ}$ \\
\hline Sul $-\mathrm{S}$ & $135^{\circ}$ a $224^{\circ}$ \\
\hline Leste $-\mathrm{L}$ & $45^{\circ}$ a $134^{\circ}$ \\
\hline Oeste $-\mathrm{O}$ & $225^{\circ}$ a $314^{\circ}$ \\
\hline
\end{tabular}

32 Bauer, E.; Souza, J. S.; Mota, L. M. G. 
Para o estudo específico da incidência de ocorrência (frequência) das zonas da fachada, se determina o Fator de Danos da Zona $\left(\mathrm{FD}_{\mathrm{z}}\right)$, o qual permite uma análise particular de cada zona no conjunto das demais. A Equação 4 traz a quantificação associada, sendo esse indicador calculado para cada zona da amostra.

$F D_{z}=\frac{A_{d z}}{A}$

Onde:

$\mathrm{FD}_{z}$ é o Fator de Danos da Zona;

$\mathrm{A}_{\mathrm{dz}}$ é a área degradada na zona respectiva da amostra de fachada em metros quadrados; e

A é a área total da amostra (m ).

A investigação da intensidade ou gravidade da degradação para as zonas é determinada pelo Fator de Danos Ponderado $\left(\mathrm{FD}_{\mathrm{w}}\right)$. Neste caso a área degradada da zona é dividida pela área da zona na amostra, conforme coloca a Equação 5. Esse indicador também é calculado para cada zona da amostra.

$F D_{w}=\frac{A_{d z}}{A_{z}}$

Eq. 5

Onde:

FD $_{\mathrm{w}}$ é o Fator de Danos Ponderado;

$\mathrm{A}_{\mathrm{dz}}$ é a área degradada da zona analisada na amostra (m ); e

$\mathrm{A}_{\mathrm{z}}$ é a área total da zona na amostra (m ).

Mesmo identificando a incidência de ocorrência $\left(\mathrm{FD}_{\mathrm{z}}\right)$ e a gravidade $\left(\mathrm{FD}_{\mathrm{w}}\right)$ da degradação, existe um questionamento de criticidade. Deve-se avaliar, por exemplo, se uma condição de alta incidência e baixa gravidade pode ser mais crítica que uma condição de baixa incidência e alta gravidade. Para isso, na investigação desenvolvida por Piazzarollo (2019), se propõe um índice de gravidade obtido pela multiplicação de $\mathrm{FD}_{\mathrm{w}}$ por $\mathrm{FD}_{\mathrm{z}}$. Uma vez que $\mathrm{FD}_{\mathrm{w}}$ e $\mathrm{FD}_{\mathrm{z}}$ possuem escalas e ordem de grandeza distintas, é necessário normalizar os valores. Isso é feito se dividindo o valor obtido da amostra pelo valor máximo obtido na investigação, tanto para $\mathrm{FD}_{\mathrm{w}}$ como para $\mathrm{FD}_{\mathrm{z}}$. A Equação 6 descreve como a relação é determinada.

$I G C=\frac{F D_{z}}{F D_{z} \max } \cdot \frac{F D_{w}}{F D_{w} \max }$

Eq. 6

Onde:

IGC é o Índice de Gravidade Crítica;

$\mathrm{FD}_{\mathrm{z}}$ é o Fator de Danos da Zona;

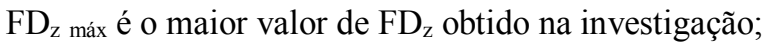

$\mathrm{FD}_{\mathrm{w}}$ é o Fator de Danos Ponderado da zona; e

$\mathrm{FD}_{\mathrm{w} \text { máx }}$ é o maior valor de $\mathrm{FD}_{\mathrm{w}}$ obtido na investigação.

\section{Resultados e discussões}

Com o enfoque da investigação da gravidade e extensão da degradação de fachadas, a partir da inspeção de edifícios em uso, os resultados observados são analisados tendo por base as diferenças entre as orientações das fachadas e da distribuição das anomalias nas diferentes zonas. A partir do desenvolvimento metodológico do enquadramento do Método de Mensuração da Degradação (MMD) é factível empregar vários indicadores que permitem desenvolver análises específicas com o viés de traduzir a degradação quantificada em termos de comportamentos que podem elucidar as principais tendências que condicionam a degradação de fachadas.

\section{Distribuição entre as anomalias investigadas}

Uma análise simples da distribuição das anomalias caracterizando as diversas tipologias observadas na amostra exibe padrões gerais nos quais essas anomalias ocorrem. Como se observa na Figura 5, do total das anomalias quantificadas se evidencia que a fissura possui maior incidência (52\%). Em contraposição, o descolamento aparece com valores baixos (1\%), o que demonstra não ser essa uma anomalia dominante. De forma diferente das fachadas de revestimento cerâmico (SILVESTRE; BRITO, 2009; SILVA, 2014; 
SOUZA, 2019), em que a predominância é por descolamento, a fachada em argamassa tem evolução distinta nos mecanismos de degradação. Em relação às anomalias superficiais se constata que as manchas (29\%) e as anomalias de pintura (17\%) se mostram relevantes no conjunto de comportamentos observados.

A análise preliminar que se apresenta permite constatar que, conforme o Quadro 1, tanto as causas como a propagação das anomalias têm mecanismos distintos e peculiares. Assim, a grande ocorrência de fissuração mostra uma forte suscetibilidade aos efeitos de esforços cíclicos e concentrados, oriundos principalmente da alvenaria e tendo por causa variações cíclicas de temperaturas e umidade. Já em relação às manchas, é de se observar a relação com a molhagem e secagem, principalmente na formação de fungos emboloradores. As falhas de pintura, ligadas, por sua vez, à radiação solar, às variações dimensionais do substrato e ao umedecimento por chuva dirigida, se manifestam no conjunto das demais anomalias. Os sistemas de pintura têm a particularidade de apresentar uma vida útil de projeto bem menor que a da fachada, onde a deficiência de manutenção e reabilitação pode ser fator decisivo na degradação amostrada.

\section{Análise da degradação em função da orientação solar}

A orientação solar da fachada (N, S, L e O) traz diferenciações sobre a atuação particular dos agentes de degradação climáticos, particularmente chuva dirigida e radiação solar. Os mecanismos dependentes da umidificação e secagem, dos esforços diferenciais devido à movimentação restringida, das movimentações por efeito térmico e umidade são todos influenciados em conjunto pela orientação. A investigação que se apresenta busca evidenciar comportamentos das anomalias diante dessas ações, de forma direta ou sinérgica.

Um dos principais indicadores de degradação aplicado pelo MMD é o Fator de Danos (FD), o qual avalia a extensão da área degradada em relação à área da amostra. No conjunto total de edifícios, para todas as amostras mapeadas, o valor de FD médio é apresentado na Tabela 3 e na Figura 6.

Figura 5 - Distribuição de anomalias nas amostras em estudo

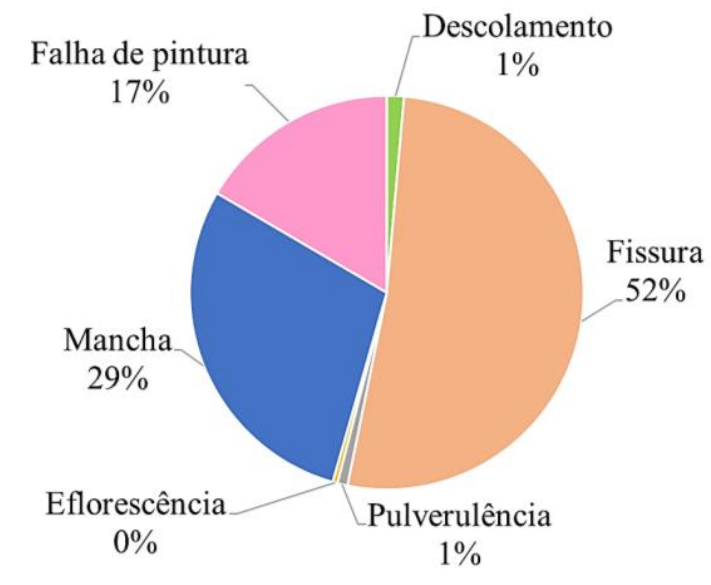

Tabela 3 - FD médio da amostra e das anomalias

\begin{tabular}{c|c|c|c|c|c|c|c}
\hline \multirow{2}{*}{ Orientação } & \multirow{2}{*}{ FD } & \multicolumn{7}{c}{ FD anom } \\
\cline { 4 - 8 } & & De.A & Fi.A & Pu.A & Ef.A & Ma.A & Pi.A \\
\hline N & 0,90 & 0,011 & 0,463 & 0,014 & 0,016 & 0,263 & 0,259 \\
S & 0,85 & 0,025 & 0,376 & 0,014 & 0,013 & 0,206 & 0,323 \\
L & 0,45 & 0,014 & 0,244 & 0,012 & 0,011 & 0,144 & 0,056 \\
O & 0,51 & 0,009 & 0,292 & 0,022 & 0,007 & 0,157 & 0,062 \\
Geral & 0,59 & 0,015 & 0,344 & 0,015 & 0,012 & 0,193 & 0,175 \\
\hline
\end{tabular}

Nota: Legenda:
De.A - Descolamento;
Fi. A - Fissura;
Pu.A - Pulverulência;
Ef.A - Eflorescência;
Ma.A - Manchas; e
Pi.A - Falha de pintura.

34 Bauer, E.; Souza, J. S.; Mota, L. M. G. 
Figura 6 - Fator de Danos médio para as amostras investigadas

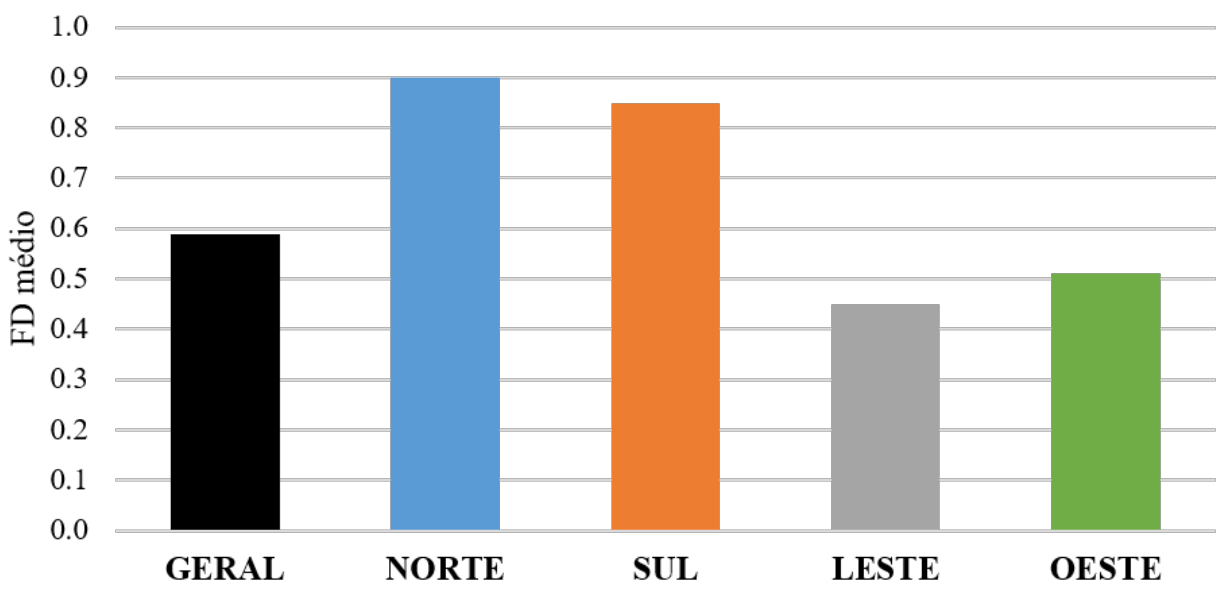

A Tabela 3 mostra os valores médios gerais para o conjunto de todas as amostras, tanto os valores diferenciados para as anomalias como o valor global do conjunto de todas as amostras. Para as orientações se apresentam os valores médios tanto do FD como de $\mathrm{FD}_{\text {anom }}$ das anomalias encontrados nas amostras para cada orientação. Observa-se que a orientação $\mathrm{N}$ é a mais degradada em relação às outras orientações de fachada, o que converge com estudos de fachadas cerâmicas nos quais apontam essa fachada como a mais crítica (BAUER; CASTRO; SILVA, 2015; SOUZA, 2016; SANTOS, 2018). Todavia, a orientação S possui também FD elevado, o que evidencia uma tendência distinta da degradação para as fachadas em argamassa.

A Figura 6 apresenta os dados de FD médio, diferenciado para as quatro orientações. Mostra-se claro que existe diferença entre os dois grupos, a saber: orientações $\mathrm{N} / \mathrm{S}$ e orientações $\mathrm{L} / \mathrm{O}$. Essa diferença é significativa e pode chegar a duas vezes o valor, como é o caso entre as orientações L e N (Tabela 3). Nesta análise não existe distinção entre as anomalias, sendo o foco uma análise global. A existência de uma tendência clara de comportamento pode ensejar que talvez parte da degradação possa ser explicada pelo conjunto de variáveis associadas à orientação. Nesse escopo se enquadram os agentes de degradação climáticos e os mecanismos por eles influenciados. Todavia, essa associação não é direta, uma vez que as anomalias são influenciadas diferentemente pelos agentes.

Sobre o padrão de comportamento para as anomalias, a Figura 7 permite a observação dos dados médios de

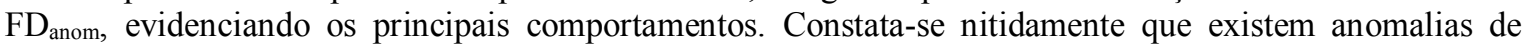
maior ocorrência, como é o caso das fissuras, manchas e anomalias de pintura. Nessas anomalias, tomandose os dados gerais (Tabela 3), se constata que fissuras apresentam valores superiores em mais de $50 \%$ das outras duas (mancha e pintura).

$\mathrm{O} F \mathrm{FD}$ e $\mathrm{FD}_{\text {anom }}$ são indicadores da incidência de ocorrência da degradação na amostra, uma vez que relacionam a área degradada com a área total da amostra. É bastante nítida a subdivisão da degradação nas anomalias mais relevantes (fissura, mancha e pintura). $O \mathrm{FD}_{\text {anom }}$ observado relata a condição de degradação do edifício em uso, ou seja, sofrendo o desgaste pela ação dos agentes de degradação (principalmente os climáticos). Assim, a fissuração se mostra atuante em todas as orientações, com predominância da orientação N.

A fachada $\mathrm{N}$ recebe grande incidência da radiação solar (Figura 2), o que pode ensejar um conjunto de esforços e movimentações de natureza térmica, com tendência a maior fissuração. Essa hipótese já pode ser refutada quando se observa o FD para a orientação S. Nesse caso essa fachada é a que recebe menos radiação no edifício, ou seja, pelo raciocínio anterior não deveria apresentar índice de fissuração tão elevado nessa análise. Essa argumentação embasa a questão de que a degradação, medida aqui pelo FD, é um resultado que deriva de vários agentes, mecanismos e fatores, não sendo possível elencar diretamente um ou outro para explicar todo o fenômeno. Deve-se ainda observar que a propagação da degradação ocorre por mecanismos muitas vezes distintos dos mecanismos de origem das anomalias (Quadro 1). Muitas vezes se busca associar os mecanismos pelos quais as anomalias surgem diretamente com a propagação da degradação, o que nem sempre é verdadeiro. 
Figura 7 - Fator de Danos médio para as anomalias e orientação

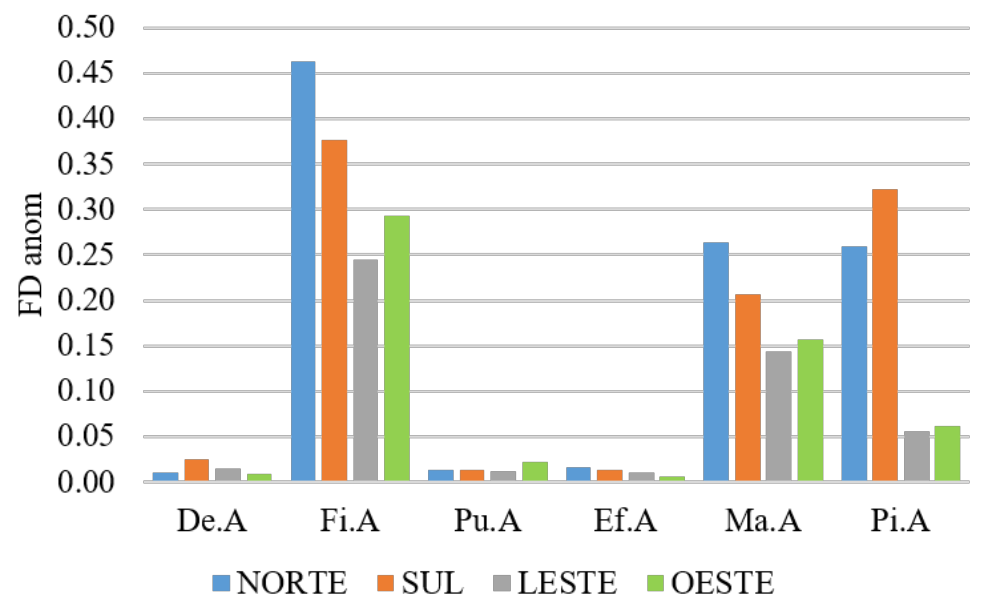

Observando outro agente de degradação climático, a chuva dirigida, Zanoni (2015) e Santos et al. (2018) observam que para Brasília, no ano climático (TMY), a orientação crítica é a noroeste (NO). Para fissura, mancha e pintura, observa-se que a orientação $\mathrm{N}$ é a mais crítica, enquanto a $\mathrm{O}$ não o é (Figura 7). Ao se observarem as tendências para mancha e pintura, se identifica inclusive que a orientação $S$ é uma das principais em termos de ocorrência. Explicar como a orientação de fachada que recebe menos chuva dirigida e menos radiação solar pode ser responsável por essas anomalias evidencia que não é só quantificando os agentes de degradação, mas, sim, estudando qual o mecanismo da anomalia no elemento do edifício, que se podem nomear possíveis relações. Zanoni (2015), empregando simulação higrotérmica em edifícios de Brasília, explica que o fator a ser analisado para manchas não é a chuva dirigida, mas, sim, o teor de umidade. No contexto, fachadas com menor incidência de radiação apresentam maior teor de umidade ao longo de todo o ano. Dessa forma, esse é um dos comportamentos que devem ser explicitados no entendimento das manchas e das diversas anomalias de superfície observadas na Figura 7.

A constatação geral é a de que, ao avaliar a incidência de ocorrência pelo indicador FD, as orientações N/S são as mais críticas, não sendo negligenciados também os valores para L/O. As principais anomalias são fissuração, manchas e falhas de pintura. Para um melhor entendimento da degradação observada, cabe observar como ocorre a distribuição da degradação pela extensão da fachada, o que se faz com o estudo da degradação nas diferentes zonas.

\section{Análise da degradação nas zonas}

$\mathrm{O}$ estudo da degradação associado às zonas busca identificar as associações que levam à degradação em anomalias de maior incidência de ocorrência e de maior gravidade. Dessa forma, o indicador $\mathrm{FD}_{\mathrm{z}}$ indica a incidência da ocorrência de degradação da zona, e o indicador $\mathrm{FD}_{\mathrm{w}}$ quantifica a gravidade de degradação. A análise desses dois indicadores de forma isolada e em conjunto permite buscar padrões de gravidade para as anomalias e para a frequência de incidência da degradação.

Os valores médios de $\mathrm{FD}_{z}$, subdivididos nas anomalias, são apresentados na Tabela 4 e na Figura 8. Observa-se que a incidência de ocorrência total, em ordem crescente, é CE, TP, TO, AB e PC. Nota-se que $\mathrm{PC}$ é a zona com um $\mathrm{FD}_{\mathrm{z}}$ consideravelmente mais alto que as demais, chegando a ser três vezes superior à zona de menor valor (CE). De forma análoga, Silva, Bauer e Castro (2014) e Bauer, Castro e Silva (2015) apontam PC como a zona de maior ocorrência de anomalias em sistemas de revestimento cerâmico. Isso pode ser interpretado como uma maior vulnerabilidade à degradação dessas zonas com maior $\mathrm{FD}_{\mathrm{z}}$, embora $\mathrm{o}$ que se avalie nesse caso corresponde à frequência de casos (incidência de ocorrência). 
Tabela 4 - Incidência de ocorrência da degradação e anomalias (FDz)

\begin{tabular}{c|c|c|c|c|c}
\hline \multicolumn{7}{c}{ FD $_{\mathbf{z}}$} \\
\hline & PC & AB & CE & TP & TO \\
\hline De.A & 0,0042 & 0,0074 & 0,0030 & 0,0035 & 0,0099 \\
Fi.A & 0,1173 & 0,0877 & 0,0236 & 0,0482 & 0,0413 \\
Pu.A & 0,0080 & 0,0048 & 0,0053 & 0,0051 & 0,0122 \\
Ef.A & 0,0068 & 0,0042 & 0,0044 & 0,0047 & 0,0055 \\
Ma.A & 0,0467 & 0,0376 & 0,0156 & 0,0641 & 0,0571 \\
Pi.A & 0,0466 & 0,0336 & 0,0142 & 0,0353 & 0,0361 \\
SOMA & 0,2297 & 0,1754 & 0,0660 & 0,1608 & 0,1621 \\
\hline
\end{tabular}

Figura 8 - Incidência de ocorrência das anomalias nas zonas - FDz

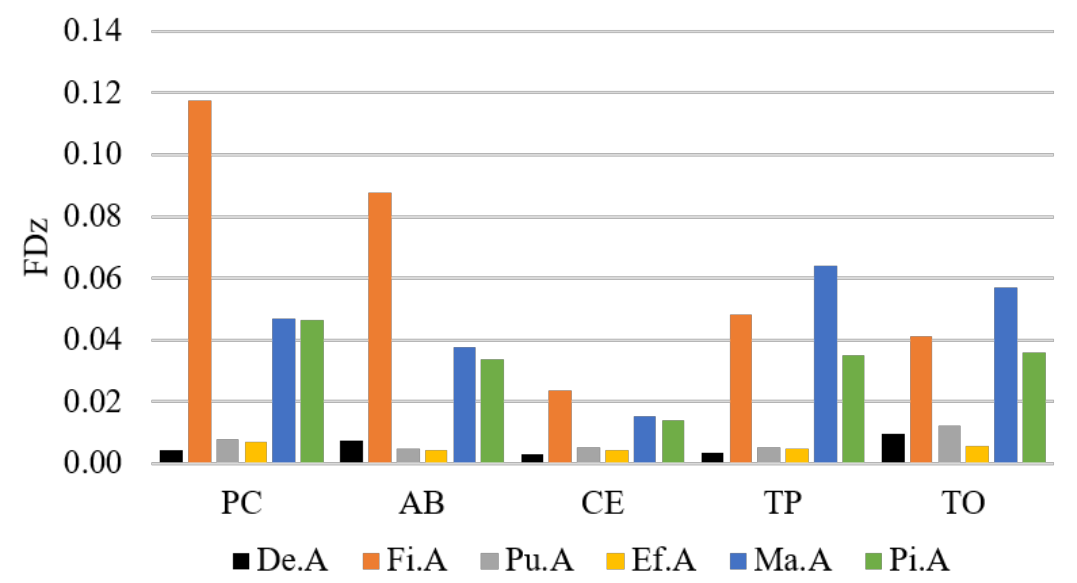

A Figura 8 compara os dados de $\mathrm{FD}_{\mathrm{z}}$ e nela se evidenciam os maiores valores para fissuras, seguidas de manchas e anomalias de pintura. Observa-se predominância da fissura para PC, AB e TP, enquanto para mancha ocorre predominância para TP e TO. CE é a zona de menor incidência de degradação, ocorrendo, nesse caso, predominância da fissuração. Outro aspecto que pode influenciar o $\mathrm{FD}_{z}$ é a proporção de áreas entre as zonas. Zonas com maior área são mais expostas aos agentes de degradação climáticos, o que pode influir no número de casos que ocorrem nelas. Assim, $\mathrm{PC}$ e AB, que possuem maiores áreas nas amostras (Tabela 2), são mais expostas aos agentes de degradação. Por sua vez, o $\mathrm{FD}_{\mathrm{z}}$ é um indicador que aponta $\mathrm{o}$ que ocorre na amostra quanto à incidência, pelo que se deve interpretá-lo adequadamente.

A gravidade ou intensidade da degradação, quantificada pelo $\mathrm{FD}_{\mathrm{w}}$, é apresentada na Tabela 5 e na Figura 9 , observando as anomalias e as respectivas zonas. São apresentados valores médios de $\mathrm{FD}_{\mathrm{W}}$ do conjunto de amostras investigado.

$\mathrm{Na}$ análise da gravidade se observa que TO e TP são as zonas com maior gravidade da degradação. As demais zonas - PC, AB e CE - têm gravidade similar, com alternância entre os índices das anomalias.

As anomalias mais críticas são as fissuras, seguidas das manchas e das falhas de pintura, tanto para a análise de incidência como também para a gravidade. É interessante observar que para TO as anomalias descolamento, pulverulência e eflorescência se mostram incrementadas em relação às demais zonas. Em específico para a região de $\mathrm{TO}$, se pode associar a ação direta da chuva dirigida, a qual é de maior valor especificamente para o topo e laterais superiores da fachada (BLOCKEN; DEROME; CARMELIET, 2013; ZANONI, 2015). Pode-se seguramente afirmar que essa região é suscetível a grande incidência de molhagem ao longo do ano. 
Tabela 5 - Gravidade da degradação nas zonas e anomalias - FDw

\begin{tabular}{c|c|c|c|c|c}
\hline \multicolumn{6}{c}{ FD $_{\mathbf{w}}$} \\
\hline & PC & AB & CE & TP & TO \\
\hline De.A & 0,0118 & 0,0370 & 0,0594 & 0,0260 & 0,0984 \\
Fi.A & 0,3481 & 0,2833 & 0,2358 & 0,3365 & 0,4415 \\
Pu.A & 0,0186 & 0,0320 & 0,0485 & 0,0378 & 0,1177 \\
Ef.A & 0,0181 & 0,0156 & 0,0343 & 0,0312 & 0,0548 \\
Ma.A & 0,1178 & 0,1275 & 0,1529 & 0,4072 & 0,6268 \\
Pi.A & 0,1468 & 0,1101 & 0,1671 & 0,2175 & 0,3197 \\
SOMA & 0,6613 & 0,6055 & 0,6980 & 1,0562 & 1,6590 \\
\hline
\end{tabular}

Figura 9 - Gravidade da degradação nas zonas - FDw

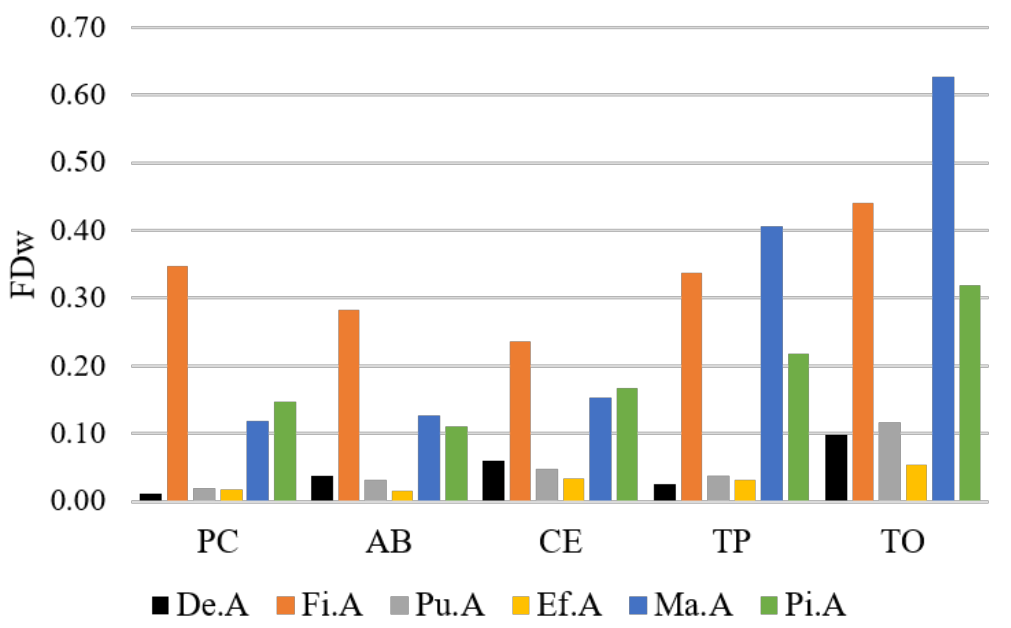

Outro agente de atuação importante é a radiação solar, não somente na fachada, mas na cobertura do edifício. Essa incidência de radiação é cíclica (ciclos diários), e seu efeito em termos de variações de temperatura gera deformações e esforços associados à amplitude de temperaturas observada nos elementos. Assim, a zona TO da fachada recebe ações de molhagem/secagem e ações termomecânicas importantes, de forma diferenciada das demais zonas da fachada. Associando-se anomalias e mecanismos, pode-se argumentar que fissuras e descolamentos dependem mais dos esforços e deformações, enquanto manchas, pulverulência, fissuras, eflorescência e anomalias de pintura se relacionam mais à molhagem/secagem (chuva dirigida).

Na propagação, quando ocorre o incremento da anomalia, o efeito dos ciclos diários de esforços, e dos ciclos umidificação/secagem, bem como o efeito sinérgico entre anomalias (permitindo, por exemplo, o ingresso de agentes), faz com que outros comportamentos ocorram. Conforme o exemplo da Figura 1, em que a fissuração evolui para degradação generalizada, uma etapa avançada de degradação (para amostras com idade mais elevada) terá maior gravidade $\left(\mathrm{FD}_{\mathrm{w}}\right)$ e maior incidência de ocorrência $\left(\mathrm{FD}_{\mathrm{z}}\right)$. Os maiores valores de descolamento, pulverulência e eflorescência na zona TO podem ser analisados como um efeito de possível propagação das fissuras.

A ordem de importância da gravidade das anomalias em PC, AB e CE é também bastante similar, com ênfase para a fissuração, seguida de manchas e anomalias de pintura. Em termos de gravidade não existe grande diferença entre esses três grupos, conforme mostra a Figura 9. Avalia-se que numa tendência de comportamento geral não se observa diferença entre gravidade para anomalias principais. As diferenças passam a ser observáveis nas anomalias secundárias, como mostra o Quadro 4.

Em termo de gravidade se pode concluir que TO e TP são zonas mais críticas com intensidade de degradação mais relevante, tendo como anomalias importantes manchas, anomalias de pintura e fissuração. As demais zonas - CE, AB e PC - têm menor gravidade, destacando-se a anomalia de fissuração (Quadro 4). 
Associar a orientação ao estudo da degradação das zonas conduz a uma análise de um conjunto de variáveis em que a degradação pode ser observada também com o enfoque das anomalias. Para uma análise de criticidade, empregando o Índice de Gravidade Crítica (IGC) (Equação 6), se obtêm os resultados da Tabela 6. São identificados na Tabela 6 os valores intermediários e superiores observados na totalidade das amostras estudadas.

Quadro 4 - Avaliação das zonas pela incidência e gravidade das anomalias

\begin{tabular}{|c|c|c|c|c|}
\hline & \multicolumn{2}{|c|}{ Incidência $\left(\mathrm{FD}_{\mathrm{z}}\right)$} & \multicolumn{2}{|c|}{ Gravidade $\left(\mathrm{FD}_{\mathrm{w}}\right)$} \\
\hline & & Anomalia & & Anomalia \\
\hline Zona & Principal & Secundária & Principal & Secudária \\
\hline PC & Fissura & Mancha, falha de pintura & Fissura & Falha de pintura, mancha \\
\hline $\mathbf{A B}$ & Fissura & Mancha, falha de pintura & Fissura & Mancha, falha de pintura \\
\hline $\mathbf{C E}$ & Fissura & Mancha, falha de pintura & Fissura & Falha de pintura, mancha \\
\hline TP & Mancha & Fissura, falha de pintura & Mancha & Fissura, falha de pintura \\
\hline TO & Mancha & Fissura, falha de pintura & Mancha & Fissura, falha de pintura \\
\hline
\end{tabular}

Tabela 6 - Índice de Gravidade Crítica (IGC) para as anomalias, orientações e zonas componentesda fachada

\begin{tabular}{|c|c|c|c|c|c|c|}
\hline \multirow{2}{*}{ Orientação } & \multirow{2}{*}{ Anomalia } & \multicolumn{5}{|c|}{$\overline{\text { IGC }}$} \\
\hline & & PC & $\mathbf{A B}$ & CE & TP & TO \\
\hline \multirow{6}{*}{ Norte } & $\overline{\text { De.A }}$ & 0,0003 & 0,0002 & 0,0006 & 0,0012 & 0,0055 \\
\hline & Fi.A & $\Delta 0,4502$ & $\Delta 0,4912$ & 0,0555 & $\mathbf{\Delta} \mathbf{0 , 3 6 8 7}$ & $\Delta \mathbf{0 , 2 8 9 9}$ \\
\hline & Pu.A & 0,0004 & 0,0005 & 0,0027 & 0,0011 & 0,0509 \\
\hline & Ef.A & 0,0029 & 0,0000 & 0,0000 & 0,0019 & 0,0004 \\
\hline & Ma.A & 0,0958 & • 0,1589 & 0,0370 & $\Delta \mathbf{0 , 2 5 4 5}$ & $\Delta 0,2944$ \\
\hline & Pi.A & 0,1053 & 0,0820 & 0,0396 & • 0,1657 & $\mathbf{\Delta} \mathbf{0 , 6 5 9 2}$ \\
\hline \multirow{6}{*}{ Sul } & De.A & 0,0009 & 0,0039 & 0,0046 & 0,0016 & 0,0225 \\
\hline & Fi.A & $\mathbf{\Delta} \mathbf{0 , 3 7 6 3}$ & $\Delta 0,4292$ & $\bullet 0,1208$ & $\Delta \mathbf{0 , 2 2 2 8}$ & $\Delta 0,2640$ \\
\hline & Pu.A & 0,0025 & 0,0007 & 0,0009 & 0,0019 & 0,0050 \\
\hline & Ef.A & 0,0002 & 0,0000 & 0,0000 & 0,0014 & 0,0155 \\
\hline & Ma.A & - 0,1373 & 0,0671 & 0,0391 & 0,0999 & $\Delta 0,2456$ \\
\hline & Pi.A & $\mathbf{\Delta 0 , 3 0 7 1}$ & $\Delta 0,2478$ & $\bullet 0,1347$ & $\Delta \mathbf{0 , 2 3 6 9}$ & $\mathbf{\Delta} \mathbf{0 , 3 2 2 0}$ \\
\hline \multirow{6}{*}{ Leste } & De.A & 0,0001 & 0,0022 & 0,0014 & 0,0001 & 0,0131 \\
\hline & Fi.A & • 0,1955 & 0,0889 & 0,0219 & 0,0525 & 0,0862 \\
\hline & Pu.A & 0,0004 & 0,0011 & 0,0004 & 0,0007 & 0,0025 \\
\hline & Ef.A & 0,0011 & 0,0008 & 0,0018 & 0,0006 & 0,0005 \\
\hline & Ma.A & 0,0128 & 0,0082 & 0,0112 & $\Delta 0,2224$ & $\Delta \mathbf{0 , 2 5 8 3}$ \\
\hline & Pi.A & 0,0097 & 0,0046 & 0,0053 & 0,0095 & 0,0128 \\
\hline \multirow{6}{*}{ Oeste } & De.A & 0,0003 & 0,0016 & 0,0004 & 0,0005 & 0,0009 \\
\hline & Fi.A & $\Delta 0,2675$ & • 0,1478 & 0,0311 & 0,0822 & 0,0991 \\
\hline & Pu.A & 0,0088 & 0,0017 & 0,0045 & 0,0055 & 0,0108 \\
\hline & Ef.A & 0,0002 & 0,0001 & 0,0005 & 0,0000 & 0,0025 \\
\hline & Ma.A & 0,0264 & 0,0281 & 0,0110 & • 0,1525 & $\Delta 0,2021$ \\
\hline & Pi.A & 0,0298 & 0,0061 & 0,0033 & 0,0184 & 0,0167 \\
\hline
\end{tabular}

Nota: Legenda:

$\Delta$ IGC > 0,219 (valores superiores); e

- $0,109>\mathrm{IGC} \leq 0,219$ (valores intermediários).

A análise de criticidade mostra associações das anomalias com as zonas e com as orientações. De forma convergente, é possível a partir da análise da distribuição dos valores intermediários e superiores de IGC da Tabela 6 identificar que:

(a) fissura é a anomalia mais crítica em todas as orientações, e PC, que possui maior área na amostra, tem alto IGC para fissura em todas as orientações; 
(b) TO apresenta degradação em todas as orientações, principalmente no caso de manchas e anomalias de pintura. Em virtude de seu posicionamento na fachada, constitui a zona mais fortemente exposta a ciclos de molhagem e secagem, incidência da radiação e efeitos da cobertura do edifício. $\mathrm{Na}$ orientação $\mathrm{N}$ e $\mathrm{S}$ as fissuras têm IGC elevado;

(c) TP e PC já são influenciadas nitidamente pela orientação preferencial das fachadas N e S. Talvez a influência da cobertura seja menor nessas zonas. A fissuração é idêntica, mas as manchas diminuem na orientação $\mathrm{S}$;

(d) em PC a criticidade da fissura se mostra importante em todas as orientações. A fissura parece ser uma anomalia inerente ao revestimento em argamassa. Significativa retração inicial, efeitos da movimentação da estrutura e da base do revestimento ao longo do tempo podem ser hipóteses que justifiquem essa observação;

(e) $\mathrm{AB}$ apresentam basicamente a fissura como anomalia crítica, ocorrendo principalmente nas orientações $\mathrm{N}, \mathrm{S}$ e $\mathrm{O}$;

(f) CE são as zonas de menor criticidade da degradação;

(g) nas orientações L e $\mathrm{O}$ as anomalias de manchas e pintura são menos críticas. Entre essas orientações a radiação solar é similar ao longo do ano (e intermediária entre sul e norte). Efeitos de secagem talvez possam contribuir para um menor IGC; e

(h) descolamento, pulverulência e eflorescência são insignificantes no conjunto global de dados.

\section{Conclusões}

A degradação não pode ser explicada somente pelo estudo das anomalias. O que se obtém é uma análise de tendências que deve ser corretamente associada ao entendimento da degradação. A inspeção de edifícios em uso tem como resultado uma análise global dos efeitos que afetam a degradação. A evolução da degradação e das anomalias é o resultado de ações e respostas conjuntas de todos os intervenientes no processo. Nesse contexto apresentam-se as principais conclusões a seguir:

(a) a fissura é a principal anomalia observada nos edifícios e se distribui em todas as orientações da fachada. Essa é uma característica da distribuição da anomalia nos edifícios;

(b) a zona de maior incidência de degradação $\left(\mathrm{FD}_{\mathrm{z}}\right)$ é o topo $(\mathrm{TO})$, e a de maior gravidade $\left(\mathrm{FD}_{\mathrm{w}}\right)$ é paredes contínuas $(\mathrm{PC})$. Em relação à criticidade, topo $(\mathrm{TO})$ e paredes contínuas $(\mathrm{PC})$ apresentam os maiores valores de IGR;

(c) as orientações norte e sul apresentam maior incidência de ocorrência (FD) principalmente pela maior ocorrência das anomalias de pintura e manchas. A fissura não possui tendência dependente da orientação;

(d) a modelação da vida útil deve estar atenta principalmente aos efeitos sinérgicos entre anomalias e agentes, principalmente porque eles podem explicar grande parte dos comportamentos da propagação da degradação. É nítido que as taxas de degradação se modificam e se incrementam com a evolução do tempo. Assim, as associações de criticidade investigadas mostram uma resposta importante, apontando as zonas mais críticas e as anomalias dominantes no processo; e

(e) requisitos e critérios de desempenho em relação ao comportamento de fissuração das fachadas são muito adequados. Essa é a anomalia de maior importância e de maior gravidade nos revestimentos em argamassa.

\section{Referências}

ADDESSI, D. et al. Multiscale analysis of in-plane masonry walls accounting for degradation and frictional effects. International Journal for Multiscale Computational Engineering, v. 18, n. 2, p. 159-180, 2020.

AMERICAN SOCIETY FOR TESTING AND MATERIALS. E 632-81: standard practice for developing accelerated tests to a prediction of the service life of building components and materials. Philadelphia, 1996.

ASSOCIAÇÃO BRASILEIRA DE NORMAS TÉCNICAS. NBR 15220-3: desempenho térmico de edificações: parte 3: zoneamento bioclimático brasileiro e diretrizes construtivas para habitações unifamiliares de interesse social. Rio de Janeiro, 2005.

ASSOCIAÇÃO BRASILEIRA DE NORMAS TÉCNICAS. NBR 15575-1: edificações habitacionais: desempenho: parte 1: requisitos gerais. Rio de Janeiro, 2013. 
BAUER, E. et al. Relative importance of pathologies in the severity of facade degradation. Journal of Building Pathology and Rehabilitation, v. 5, n. 1, p. 1-10, 2020.

BAUER, E.; CASTRO, E. K.; SILVA, M. N. B. Estimativa da degradação de fachadas com revestimento cerâmico: estudo de caso de edifícios de Brasília. Cerâmica, v. 61, p. 151-159, 2015.

BAUER, E.; SOUZA, J. S.; PIAZZAROLLO, C. B. Application of the degradation measurement method in the study of facade service life. Building Pathology, Durability and Service Life, v. 12, 105-119, 2020.

BLOCKEN, B.; DEROME, J.; CARMELIET, J. Rainwater runoff from building facades: a review.

Building and Environment, v. 60, p. 339-361, 2013.

BRITISH STANDARDS INSTITUTION. BS ISO 15686-1: buildings and constructed assets: service life planning: part 1: general principles and framework. London, 2011.

BRITISH STANDARDS INSTITUTION. BS ISO 15686-10: buildings and constructed assets: service life planning: part 10: When to assess functional performance. London, 2010.

BRITISH STANDARDS INSTITUTION. BS ISO 15686-2: buildings and constructed assets: service life planning: part 2: service life prediction procedures. London, 2012.

CAVALAGLI, N. et al. Hierarchical environmental risk mapping of material degradation in historic masonry buildings: an integrated approach considering climate change and structural damage. Construction and Building Materials, v. 215, p. 998-1014, 2019.

CÓIAS, V. Inspeções e ensaios na reabilitação de edifícios. 2. ed. Lisboa: IST, 2009.

DIAS, J. L. et al. Neural networks applied to service life prediction of exterior painted surfaces. Building Research \& Information, v. 42, n. 3, p. 371-380, 2014

FLORES-COLEN, I. et al. Drying index for in-service physical performance assessment of renders. Construction and Building Materials, v. 112, p. 1101-1109, 2016.

FLORES-COLEN, I. Metodologia de avaliação do desempenho em serviço de fachadas rebocadas na óptica da manutenção predictiva. Lisboa, 2009. Tese (Doutorado em Engenharia Civil) - Instituto Superior Técnico, Universidade Técnica de Lisboa, Lisboa, 2009.

FLORES-COLEN, I.; BRITO, J.; FREITAS, V. Stains in facades' rendering: diagnosis and maintenance techniques' classification. Construction and Building Materials, v. 22, p. 211-221, 2008.

GARRIDO, M. A.; PAULO, P. V.; BRANCO, F. A. Service life prediction of façade paint coatings in old buildings. Construction and Building Materials, v. 29, p. 394-402, 2012.

GASPAR, P. L.; BRITO, J. Durabilidade, estados limite e vida útil de rebocos em fachadas. In: CONGRESSO NACIONAL DE ARGAMASSAS DE CONSTRUÇÃO, 3., Lisboa, 2010. Anais [...] Lisboa, 2010.

GASPAR, P.; BRITO, J. Quantifying environmental effects on cement-rendered facades: a comparison between different degradation indicators. Building and Environment, v. 43. n. 11, p. 1818-1828, 2008.

INTERNATIONAL COUNCIL FOR RESEARCH AND INNOVATION IN BUILDING AND CONSTRUCTION. CIB Report Publication 295: guide and bibliography to service life and durability research for buildings and components. Delft, 2004.

INTERNATIONAL COUNCIL FOR RESEARCH AND INNOVATION IN BUILDING AND CONSTRUCTION. CIB Report Publication 393: a state-of-the-art report on building pathology. Delft, 2013.

MACIEL, A. A. Projeto bioclimático em Brasília: estudo de caso em edifício de escritórios. Florianópolis, 2002. Dissertação (Mestrado em Engenharia Civil) - Universidade Federal de Santa Catarina, Florianópolis, 2002.

MADUREIRA, S. et al. Maintenance planning of facades in current buildings. Construction and Building Materials, v. 147, p. 790-802, 2017.

PEREIRA, C. et al. Urgency of repair of building elements: prediction and influencing factors in façade renders. Construction and Building Materials, v. 249, p.1-16, 2020.

PEREIRA, C.; DE BRITO, J.; SILVESTRE, J. D. Contribution of humidity to the degradation of façade claddings in current buildings. Engineering Failure Analysis, v. 90, p. 103-115, 2018. 
PIAZZAROLLO, C. B. Estudo da evolução e da gravidade da degradação nas diferentes zonas componentes da fachada. Brasília, 2019. Dissertação (Mestrado em Estruturas e Construção Civil) Universidade de Brasília, Brasília, 2019.

RAMIREZ, R. et al. Bond behavior degradation between FRP and masonry under aggressive environmental conditions. Mechanics of Advanced Materials and Structures, v. 26, p. 6-14, 2019.

RORIZ, M. Correções nas irradiâncias e iluminâncias dos arquivos EPW da base ANTAC. Grupo de Trabalho sobre Conforto e Eficiência Energética de Edificações. ANTAC - Associação Nacional de Tecnologia do Ambiente Construído. São Carlos, 2012. Disponível em:

http://www.labeee.ufsc.br/downloads/arquivosclimaticos/formato-epw. Acesso em: 5 jan. 2020.

SÁ, G. et al. Statistical survey on inspection, diagnosis and repair of wall renderings. Journal of Civil Engineering and Management, v. 21, n. 5, p. 623-636, 2015.

SANTOS, A. C. Avaliação do desempenho potencial de duas soluções de revestimentos argamassados em função do risco de formação de fungos emboloradores no interior de edificações na cidade de São Paulo. São Paulo, 2019. 193 f. Dissertação (Mestrado em Habitação: Planejamento e Tecnologia) - Instituto de Pesquisas Tecnológicas do Estado de São Paulo, São Paulo, 2019.

SANTOS, D. G. Estudo da vida útil e degradação de fachadas em argamassa a partir da inspeção de edifícios. Brasília, 2018. 136 f. Dissertação (Mestrado em Estruturas e Construção Civil) - Universidade de Brasília, Brasília, 2018.

SANTOS, D. G. et al. Mensuração e distribuição de patologias na degradação de fachadas em argamassa. In: PATORREB CONFERENCE ON PATHOLOGY AND REHABILITATION OF BUILDINGS, 6., Rio de Janeiro, 2018. Proceedings [...] Rio de Janeiro, 2018.

SILVA, A. et al. Statistical models applied to service life prediction of rendered facades. Automation in Construction, v. 30, p. 151-160, 2013.

SILVA, M. N. B. Avaliação quantitativa da degradação e vida útil de revestimentos de fachada: aplicação ao caso de Brasília/DF. Brasília, 2014. Tese (Doutorado em Estruturas e Construção Civil) Universidade de Brasília, Brasília, 2014.

SILVA, M. N. B.; BAUER, E.; CASTRO, E. K. Avaliação da degradação em sistemas de revestimento cerâmico de fachadas de Brasília. In: SIMPÓSIO DE ARGAMASSAS E SOLUÇÕES TÉRMICAS DE REVESTIMENTO, 1., Coimbra, 2014. Anais [...] Coimbra, 2014.

SILVESTRE, J. D.; BRITO, J. Ceramic tiling inspection system. Construction and Building Materials, v. 23, p. 653-668, 2009.

SOUZA, J. et al. Application of a graphical method to predict the service life of adhesive ceramic external wall claddings in the city of Brasília, Brazil. Journal of Building Engineering, v. 19, p. 1-13, 2018.

SOUZA, J. et al. Evaluation of the deterioration of ceramic claddings by application of artificial neural networks. Journal of Performance of Constructed Facilities, v. 34, n. 5, p. 1-10, 2020.

SOUZA, J. S. Evolução da degradação de fachadas: efeito dos agentes de degradação e dos elementos constituintes. Brasília, 2016. 114 f. Dissertação (Mestrado em Estruturas e Construção Civil) - Universidade de Brasília, Brasília, 2016.

SOUZA, J. S. Impacto dos fatores de degradação sobre a vida útil de fachadas de edifícios. Brasília, 2019. Tese (Doutorado em Estruturas e Construção Civil) - Universidade de Brasília, Brasília, 2019.

ZANONI, V. A. G. Influência dos agentes climáticos de degradação no comportamento higrotérmico de fachadas em Brasília. Brasília, 2015. Tese (Doutorado em Arquitetura e Urbanismo). Universidade de Brasília, Brasília, 2015.

\section{Agradecimentos}

Os autores agradecem ao apoio do Conselho Nacional de Desenvolvimento Científico e Tecnológico (CNPq) e da Universidade de Brasília (UnB). 


\section{Elton Bauer}

Departamento de Engenharia Civil e Ambiental | Universidade de Brasília | Campus Universitário Darcy Ribeiro | Brasília - DF - Brasil | CEP 70910-900 | Tel.: (61) 3107-1004 | E-mail: elbauerlem@gmail.com

\section{Jéssica Siqueira Souza}

Departamento de Engenharia Civil e Ambiental | Universidade de Brasília | E-mail: jss.siqueira@gmail.com

\section{Larissa Mara Gonçalves Mota}

Departamento de Engenharia Civil e Ambiental | Universidade de Brasília | E-mail: larissagmota@gmail.com

\section{Ambiente Construído}

Revista da Associação Nacional de Tecnologia do Ambiente Construído

Av. Osvaldo Aranha, $99-3^{\circ}$ andar, Centro

Porto Alegre - RS - Brasil

$$
\text { CEP } 90035-190
$$

Telefone: +55 (51) 3308-4084

www.seer.ufrgs.br/ambienteconstruido www.scielo.br/ac

E-mail: ambienteconstruido@ufrgs.br 